\title{
Heat exchangers for solar pond applications
}

\author{
R. L. Frederick \& C. Riobó \\ Departamento de Ingeniería Mecánica, Universidad de Chile, Chile
}

\begin{abstract}
The use of solar energy for supplying heat to industrial processes is a very interesting possibility in countries having high solar energy resources. Solar ponds are collectors and accumulators that have been used as reliable sources of process heat. Transient thermal models can help in selecting suitable heat exchangers and operating conditions for ponds. Matching the energy requirements of a steady state process to the dynamics of an essentially transient energy collecting device as a solar pond is key to the economic feasibility of a process using this kind of energy source. A thermal model is used here for describing the thermal dynamics of solar ponds and for choosing heat exchangers and operating conditions for supply of process heat to a particular industrial process in northern Chile. It is found that solar ponds can supply the required heat to the process for nearly half the operating time, but the thermal efficiency of their use is low when strict process requirements are to be met.
\end{abstract}

Keywords: solar ponds, thermal modelling, heat exchanger specification.

\section{Introduction}

Solar ponds have been known to be large scale solar collectors and accumulators for more than half a century. Due to their storage capacity, they have been considered as reliable and stable, long term sources of energy for industrial processes requiring low to medium enthalpy heat inputs, irrespective of the season. One severe drawback of solar ponds for energy collection is their moderate efficiency as solar collectors, caused by the heavy thermal losses they undergo by evaporation in dry climates. In arid zones there is a serious problem of water supply for filling the pond the first time and providing make up water.

Solar ponds rely on the density variation of aqueous salt solutions. Density decreases with increasing temperature and increases with growth in salt concentration (salinity). Therefore, a saline pond is built by carefully depositing successive brine layers of decreasing salt concentration [1]. Exposed to solar 
radiation, which is selectively absorbed by the brine, three distinctive layers will develop: a thick lower convective zone (LCZ) of high salinity and temperature, a middle, thick, nearly stagnant layer with linear vertical salinity and temperature gradients (non - convective zone, NCZ) and a thin, low salinity layer exposed to the winds and environmental conditions (upper convective zone, UCZ). The time needed to develop stable linear temperature and concentration profiles in the NCZ is of the order of a year.

Heat exchangers for recovery of heat from solar ponds and delivery of this heat to a process are the subject of the present paper. The specification of these heat exchangers requires careful analysis of compatibility between the proposed heat transfer rate and the storage capacity of the solar pond as well as consideration of the rate of heat removal which is safe for maintaining the stability of the pond [2]. Another difficulty is to match the heat demand of a steady state process to the available heat from a solar pond which is essentially time dependent.

The conventional methods of heat extraction from a solar pond are: use of an internal heat exchanger, located in the LCZ. Heat is extracted my means of an auxiliary fluid inside the heat exchanger. The second method is to extract brine from the top of the LCZ, passing it through an external heat exchanger and then return it to the bottom of the LCZ. It is harder to get a high overall heat transfer coefficient in the first alternative, because of restrictions on the flow rate and velocity of the brine in the pond. Therefore, the second alternative will be considered in this paper.

The context of application of this work is the mining industry in northern Chile, a region in which solar radiation is one of the highest in the world because of the latitude (18 to $24^{\circ}$ South) and a high atmospheric transparency which prevails over at least 11 months of the year. Low temperature hydrometallurgical extractive processes, like electro-winning require the heating of electrolytes to temperatures of about $55^{\circ} \mathrm{C}$, which can be obtained by heat exchange with solar pond brines, which reach temperatures of $99^{\circ} \mathrm{C}$ at the bottom of the pond. In principle, the thermal storage capabilities of solar ponds make them very appropriate as energy sources for nearly continuous supply of heat, with variations due to daily and seasonal cycles. Large solar ponds have a long history of development in northern Chile, associated with the recovery of nitrates and lithium salts from Salar de Atacama. Recent applications of solar energy recovery for electro-winning have been energized by flat plate solar collectors with accumulation tanks instead of solar ponds [3].

In this paper we consider energy recovery from square solar ponds of different sizes. In 3.1 we simulate the construction of the temperature gradient, starting from a pond in which the salinity gradient has been created artificially. The subsequent temperature evolution without heat extraction is also described. In 3.2, we use fixed heat extraction rates to determine the maximum allowable heat extraction rates for each pond size. Finally, in 3.2 we consider the coupling of the pond with the industrial process in order to describe the thermal dynamics of heat extraction and to look for conditions of efficient use of the solar pond. 


\section{Thermal model}

A model of the long term, transient behaviour of the temperature in a solar pond is used to study the interaction of the pond with the process through a heat exchanger. The site selected is located at $-22.81^{\circ}$ latitude and $-69.52^{\circ}$ longitude, near the city of Calama, Chile. Solar radiation and meteorological data for the site were obtained by means of the Solar Energy Explorer [4].

Table 1: Monthly averaged radiation, temperature and wind speed data for 2010 .

\begin{tabular}{|l|l|l|l|l|l|l|l|l|l|l|l|l|}
\hline & Jan. & Feb. & March & April & May & June & July & Aug. & Sep. & Oct. & Nov. & Dec. \\
\hline R & 369.5 & 350.5 & 317.1 & 260.2 & 212.2 & 192.0 & 200.6 & 239.6 & 292.5 & 338.9 & 370.1 & 374.5 \\
\hline T & 19.5 & 20.0 & 19.8 & 18.4 & 16.1 & 15.7 & 13.2 & 16.4 & 16.2 & 16.7 & 17.3 & 17.5 \\
\hline W & 3.9 & 4.0 & 4.1 & 3.4 & 3.8 & 3.5 & 3.8 & 3.8 & 4.3 & 4.2 & 4.2 & 4.1 \\
\hline
\end{tabular}

The model, implemented as a Matlab code, is based on a standard onedimensional approach to the temperature field. We consider that in both the LCZ and UCZ the fluid is well mixed, so a uniform temperature can be assumed to prevail at every instant. The temperature in the NCZ varies with the vertical coordinate, so several control volumes have to be defined across its thickness. In addition, the model assumes constant thicknesses of 1.3. 1.1 and $0.7 \mathrm{~m}$ for the LCZ. NCZ and UCZ respectively. As the vertical dimensions of the pond are much lower than the horizontal ones, the temperature gradient can be assumed to depend mostly on the vertical coordinate, justifying the one-dimensional assumption. Therefore, the model is built up from energy balances for control volumes consisting of the entire LCZ and UCZ. and 22 control volumes across the NCZ. A time step of 1 hour was used throughout. The 24 heat balances are coupled and are solved simultaneously for the temperatures of the pond at every time step. Their general form for one of the control volumes is:

$$
\rho C_{p} V \frac{d T}{d t}=\sum Q_{\text {in }}-\sum Q_{\text {out }}
$$

While the specific heat and thermal conductivity are assumed constant, the density is dependent on salinity $(\mathrm{S})$ and temperature $(\mathrm{T})$ according to the expression:

$$
\rho(S, T)=\rho_{o}\left[1-\beta_{T}\left(T-T_{o}\right)+\beta_{S}\left(S-S_{o}\right)\right]
$$

Input and output heat terms are different according to the zone considered. All zones have a solar radiation input, but it is distributed unevenly in the different zones.

\subsection{Heat balances in the different zones}

Figure 1 shows the heat flow contributions for the UCZ. The heat inputs are the solar radiation and the heat conducted up from the non-convective zone. A $6 \%$ of the incident radiation is reflected on the water surface. Other losses include 
convection from the surface, $q_{c o n v}$, which depends on the wind speed $V$, according to the well-known expression $h=5.7+3.8 \mathrm{~V}\left[\mathrm{~W} / \mathrm{m}^{2} \mathrm{~K}\right]$. The evaporation loss, $q_{e v}$ depends on the latent heat of evaporation, atmospheric pressure and saturation pressure in the air at the pond surface, which evaluated at the temperature of the UCZ [5]. There is a radiation loss to the sky, which is evaluated as the loss of a grey body of emissivity 0.97 radiating to a black body which surrounds it completely. Finally, the heat loss to the ground (sides of the pond, $\mathrm{q}_{\text {cond }}$ ) is evaluated in terms of the difference between the temperature of the UCZ and the ground temperature, assumed constant at $10^{\circ} \mathrm{C}$, with an overall loss heat transfer coefficient of $0.5 \mathrm{~W} / \mathrm{m}^{2} \mathrm{~K}$.

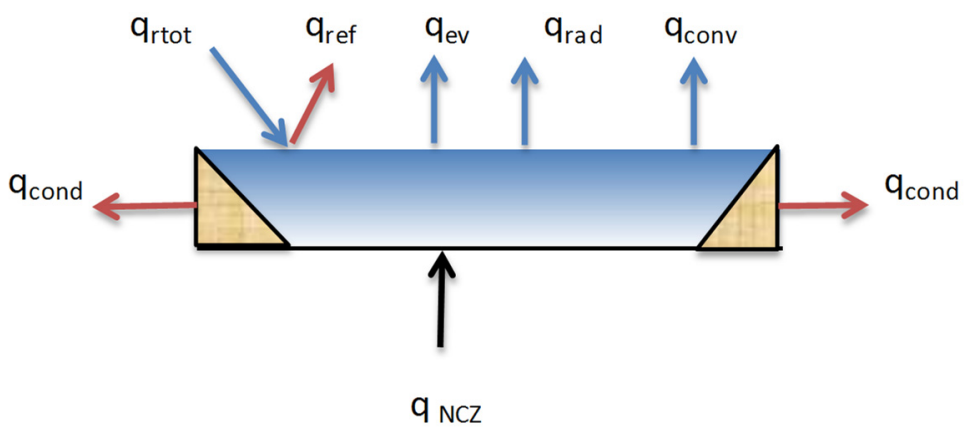

Figure 1: Heat fluxes across the boundaries of the UCZ.

The volumetric heat absorption rate as a function of the incident radiation and refraction angle can be obtained from the expression by Rabl and Nielsen [6],

$$
q_{a b s}=q_{i n c} \sum_{j=1}^{4} \frac{\varepsilon_{j}}{\cos \theta_{r}} \gamma_{j} \exp \left[-\varepsilon_{j} \frac{z}{\cos \theta_{r}}\right], \frac{W}{m^{3}}
$$

In which $\gamma_{j}, \varepsilon_{j}$ are respectively, the fraction of radiation absorbed at each wavelength range, and the extinction coefficient. The coordinate $\mathrm{z}$ is measured at the bottom of each control volume. Table 2 shows the coefficients of equation (3).

Table 2: Absorption coefficients for different wavelengths [6].

\begin{tabular}{|c|c|c|}
\hline Wavelength $[\mu \mathrm{m}]$ & $\gamma$ & $\varepsilon\left[\mathrm{m}^{-1}\right]$ \\
\hline $0.2-0.6$ & 0.237 & 0.032 \\
\hline $0.6-0.75$ & 0.193 & 0.45 \\
\hline $0.75-0.9$ & 0.167 & 3 \\
\hline $0.9-1.2$ & 0.179 & 35 \\
\hline
\end{tabular}


The heat input terms are the heat transferred by conduction from the NCZ and the radiation absorbed by the different layers. Replacing the above terms in the equation (1) one obtains:

$$
C_{p} \rho V_{U C Z} \frac{d T}{d t}=\left[q_{a b s} e_{U C Z}+q_{N C Z}-\left(q_{r a d}+q_{c o n v}+q_{e v}\right)\right] A-q_{c o n d} P e_{U C Z}
$$

where $A, P$ and $e_{u c z}$ are the cross sectional area of the pond, its perimeter and the UCZ thickness respectively. The time derivative of temperature was discretized explicitly to obtain the temperature of the zone as a function of time. The NCZ is divided into several layers, each one characterized by a temperature which evolves in time. The heat flows are the absorption of solar radiation, the conductive flows from the lower layer and to the upper layer, and the heat loss to the sides. The scheme of heat fluxes can be seen in the figures 2 and 3 which represent the ensemble of layers forming the NCZ and an individual layer within this zone, respectively. The balance equations for these zones are omitted because of lack of space.

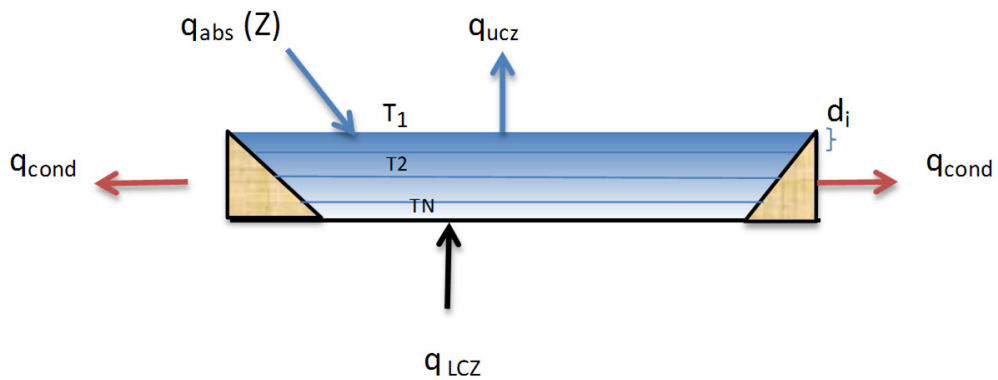

Figure 2: Heat fluxes across the boundaries of the NCZ.

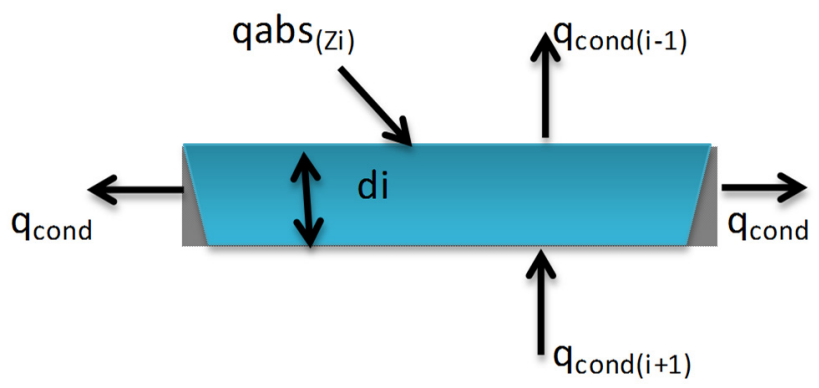

Figure 3: Heat fluxes at the boundaries of a control volume in the NCZ. 
The LCZ possesses a salt concentration near saturation. Figure 4 shows a scheme of the energy inputs and outputs in this zone, in which a uniform temperature is assumed to occur. Apart from the terms appearing in the other zones there is a remaining radiation, which was not absorbed in any of the layers and is transferred to the liquid after being absorbed by the bottom surface. This energy represents a $20 \%$ of total radiation. The most important term is the heat extraction rate, $\mathrm{Q}_{\mathrm{ext}}[\mathrm{W}]$.

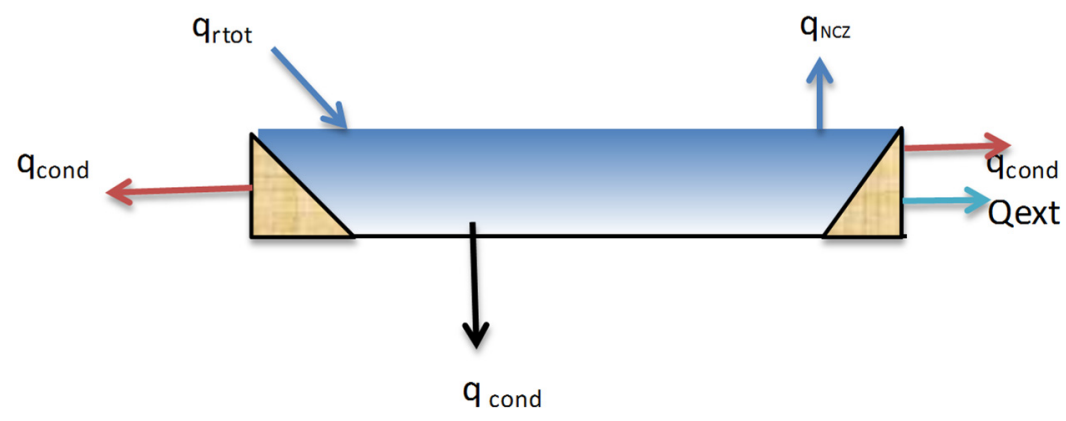

Figure 4: Heat fluxes at the lower convective zone, LCZ.

We do not have experimental data to validate the predictions of the model. However, it agrees essentially with many other models of similar level that have been proposed, e.g. [7]. The simulation of a pond starts with a developed salinity profile across the different layers, and with a uniform initial temperature of $20^{\circ} \mathrm{C}$. The salinity at the UCZ and LCZ are assumed to be $0 \%$ and $25 \%$ respectively. Simulation starts at January 1 (which corresponds to summer in the Southern Hemisphere) with the solar radiation data for year 2010, and with a relative humidity of $30 \%$. For a period of about one year the radiation heat input allows a steady temperature rise in the $\mathrm{LCZ}$ and the construction of the thermal gradient in the NCZ, with moderate daily variation of temperature in the UCZ. Once a final, time dependent state has been reached, in which the thermal losses start to compensate the heat input, heat extraction can start.

\section{Results}

\subsection{Solar pond without heat extraction $\left(Q_{\text {ext }}=0\right)$}

The general transient thermal behaviour is exemplified in Figure 5 for a $50 \times 50 \mathrm{~m}$ pond. Sensitivity to the pond dimensions is also reported. For a pond with the above characteristics and for an initial period of $8721 \mathrm{hrs}, 31.6 \%$ of the incident radiation is absorbed in the $\mathrm{UCZ}$, of which $22.4 \%$ corresponds to long wavelength. The NCZ absorbs $8.9 \%$ of incident radiation. In the LCZ, $28.5 \%$ of incident radiation is absorbed, most of it corresponding to the absorption at the pond bottom. Figure 5 shows the typical behaviour of a pond without heat extraction for a period of three years. Climatic and radiation data for the year 2010 were used for the consecutive years to avoid the effect of different conditions in the analysis. 


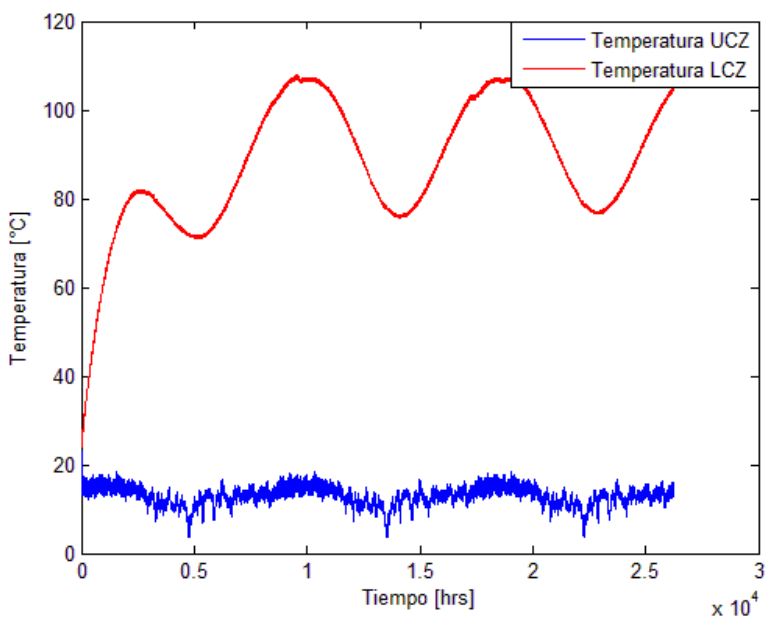

Figure 5: Temperature evolution in a $50 \times 50$ pond without heat extraction $\left(\mathrm{Q}_{\mathrm{ext}}=0\right)$.

Temperature evolution in the LCZ in the first year shows an increase, as expected, momentarily interrupted during the winter season. The time of establishment of a thermal regime suitable for heat extraction is 14 months. In the following years the LCZ displays seasonal variations of great amplitude in temperature, while the amplitude of temperature variation in the UCZ is much lower, keeping its temperature always at or below $20^{\circ} \mathrm{C}$. According to the simulations, the LCZ has been found to reach temperatures up to $107^{\circ} \mathrm{C}$ in the midsummer, exceeding the boiling point of pure water. However, this is below the boiling point of a saturated salt solution which is $109^{\circ} \mathrm{C}$ [8]. The lowest temperature in the simulations after the first year is $76^{\circ} \mathrm{C}$. These results and the seasonal temperature variation agree very well with predictions in [7].

The generation of thermal gradient in the NCZ is described in figure 6. Starting from a uniform ambient temperature across the layer, the linear temperature gradient is generated by progressive heating of the LCZ, while the temperature in the UCZ remains close to the ambient temperature. Note that the vertical coordinate points downwards with its origin at the pond surface.

\subsection{Heat extraction at constant rate. Adjustement to the process conditions}

For suitably sized ponds a regime of constant heat extraction $\left(\mathrm{Q}_{\mathrm{ext}}\right)$ was simulated. The purpose of this test was to determine the limits of heat extraction for unaided ponds with different pond sizes at which the ponds can still be operating without losing the thermal stratification. This means that we will select a heat extraction rate for which the cold return brine will not lower the LCZ temperature in such a way to destroy the thermal stratification. To this end, for different pond sizes, simulations are run with different imposed extraction rates. Only the extraction 


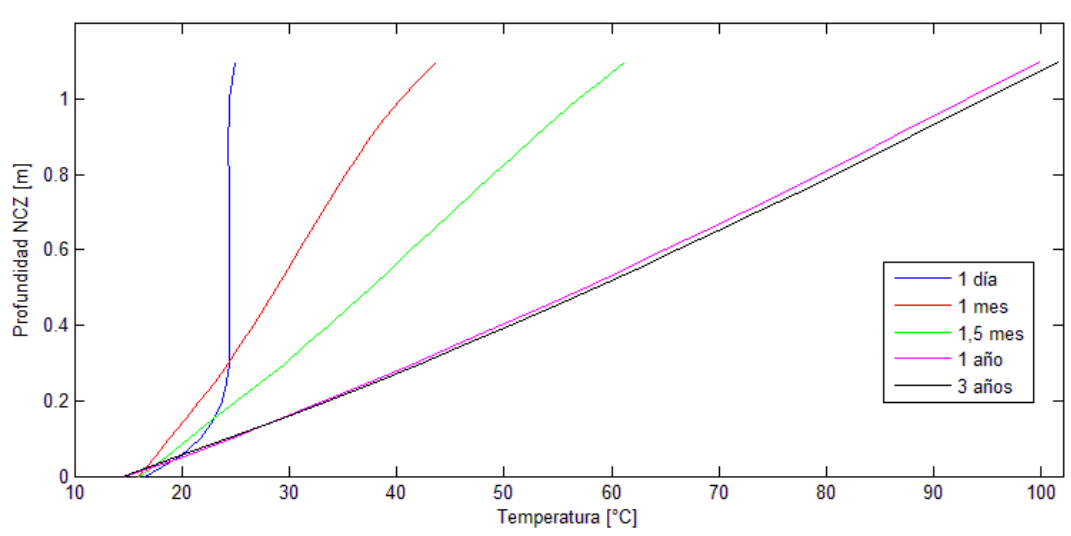

Figure 6: Thermal gradient formation in the $\mathrm{NCZ}$ at $\mathrm{Q}=0$. Curves, from left to right are for 1 day, 1 month, 1.5 months, 1 year and 3 years.

rates that maintain a linear temperature gradient in the $\mathrm{NCZ}$ after 3 years of operation can be used.

Another constraint on pond operation for this particular process is the need to ensure an extraction temperature from the $\mathrm{LCZ}$ not lower than $60^{\circ} \mathrm{C}$, because this temperature must be higher than the temperature to be reached by the electrolyte $\left(55^{\circ} \mathrm{C}\right)$. We will examine the efficiency of pond, which is the ratio of the heat extracted (at heat exchanger) to the incident radiation. It is defined for a long period (three years in this paper) in order to make this parameter representative of long term operation.

Four pond cross sections are considered: $50 \times 50 \mathrm{~m}, 70 \times 70 \mathrm{~m}, 100 \times 100 \mathrm{~m}$ and $150 \times 150 \mathrm{~m}$. For each pond cross section two fixed extraction rates were considered. Table 3 summarizes the results.

Table 3: Operating conditions of solar ponds with fixed extraction rates of brine and electrolyte $[\mathrm{kg} / \mathrm{s}]$.

\begin{tabular}{|c|c|c|c|c|c|c|c|c|}
\hline & \multicolumn{7}{|c|}{ Pond dimensions $\left[\mathrm{m}^{2}\right]$} \\
\cline { 2 - 9 } & \multicolumn{2}{|c|}{$\mathbf{5 0} \times \mathbf{5 0}$} & \multicolumn{2}{c|}{$\mathbf{7 0} \times \mathbf{7 0}$} & \multicolumn{2}{|c|}{$\mathbf{1 0 0} \times \mathbf{1 0 0}$} & \multicolumn{2}{c|}{$\mathbf{1 5 0} \times \mathbf{1 5 0}$} \\
\hline$Q_{\text {ext }}[\mathrm{kW}]$ & 35 & 45 & 80 & 95 & 170 & 200 & 440 & 500 \\
\hline \hline$T_{\max }\left[{ }^{\circ} \mathrm{C}\right]$ & 100 & 96 & 100 & 96 & 100 & 97 & 98 & 96 \\
\hline$T_{\min }\left[{ }^{\circ} \mathrm{C}\right]$ & 64 & 60 & 63 & 60 & 63 & 60 & 62 & 60 \\
\hline$\dot{m}[\mathrm{~kg} / \mathrm{s}]$ & 0.56 & 0.72 & 1.28 & 1.52 & 2.71 & 3.19 & 7.02 & 7.97 \\
\hline$\dot{m}_{e}[\mathrm{~kg} / \mathrm{s}]$ & 0.99 & 1.27 & $2, .7$ & 2.69 & 4.82 & 5.67 & 12.47 & 14.16 \\
\hline$\eta$ & 0.046 & 0.059 & 0.054 & 0.064 & 0.056 & 0.066 & 0.064 & 0.073 \\
\hline
\end{tabular}

The minimum and maximum temperatures occurring in the LCZ at different times of the year for different rates of extraction are given. These extraction rates are compatible with the pond operation, and are not too high to compromise the pond stability. However, the efficiency given in the last row is lower than usual for solar ponds because of the need to keep the temperature of the brine extracted 
at a level compatible with the needs of the process, which demands that the brine temperature entering the heat exchanger must not be lower than $60^{\circ} \mathrm{C}$. Higher efficiency could be achieved by extracting higher heat rates from the pond if lower return temperatures to the $\mathrm{LCZ}$ were allowed without making the pond unstable, but this may mean that low quality heat is being supplied to the process, or the need of a supporting heat source. To illustrate this point further we show in Table 4 some situations in which the temperatures of brines entering the heat exchanger do not comply at times with the minimum of $60^{\circ} \mathrm{C}$ necessary for the process, but pond stability is maintained.

Table 4: Operating conditions of solar ponds with higher extraction rates.

\begin{tabular}{|c|c|c|c|c|c|c|c|c|}
\hline & \multicolumn{9}{|c|}{ Pond dimensions $\left[\mathrm{m}^{2}\right]$} \\
\cline { 2 - 9 } & \multicolumn{2}{|c|}{$\mathbf{5 0} \times \mathbf{5 0}$} & \multicolumn{2}{|c|}{$\mathbf{7 0} \times \mathbf{7 0}$} & $\mathbf{1 0 0} \times \mathbf{1 0 0}$ & \multicolumn{1}{|c|}{$\mathbf{1 5 0} \times \mathbf{1 5 0}$} \\
\hline $\boldsymbol{Q}_{\text {ext }}[\boldsymbol{k W}]$ & $\mathbf{8 0}$ & $\mathbf{1 0 0}$ & $\mathbf{1 5 0}$ & $\mathbf{1 8 0}$ & $\mathbf{3 1 0}$ & $\mathbf{3 6 0}$ & $\mathbf{6 9 0}$ & $\mathbf{8 2 0}$ \\
\hline$T_{\max }\left[{ }^{\circ} \mathrm{C}\right]$ & 82 & 74 & 85 & 79 & 86 & 81 & 87 & 81 \\
\hline$T_{\min }\left[{ }^{\circ} \mathrm{C}\right]$ & 49 & 41 & 50 & 45 & 50 & 46 & 52 & 46 \\
\hline$\dot{m}[\mathrm{~kg} / \mathrm{s}]$ & 1.27 & 1.59 & 2.39 & 2.87 & 4.94 & 5.70 & 11.00 & 13.08 \\
\hline$\dot{m}_{e}[\mathrm{~kg} / \mathrm{s}]$ & 2.27 & 2.83 & 4.25 & 5.10 & 8.78 & 10.20 & 19.55 & 23.23 \\
\hline$t w e[\%]$ & 30 & 43 & 27 & 34 & 27 & 33 & 23 & 35 \\
\hline$\eta$ & 0.105 & 0.131 & 0.100 & 0.120 & 0.102 & 0.118 & 0.100 & 0.119 \\
\hline
\end{tabular}

An additional row is included giving twe, the percentage of time in which no heat can be extracted from the pond, and therefore there is the need to supply some heat by other means to the electrolyte after pasing through the main heat exchanger. Higher long term pond efficiencies are observed.

\subsection{Variable heat extraction rate from a pond connected to the process}

The operating conditions in the heat exchanger for this particular process are as follows: The process fluid (electrolyte) must enter the heat exchanger at $T_{\text {ein }}=$ $45^{\circ} \mathrm{C}$, and leave at $T_{\text {eout }}=55^{\circ} \mathrm{C}$, both temperatures fixed. If the brine can supply the required heat to take the electrolyte to $55^{\circ} \mathrm{C}$, the pond can be used without support heat. The brine, in counterflow with the electrolyte, enters the heat exchanger at $T_{L C Z}$ and leaves at $T_{\text {return }}$. Real operation often requires a fixed mass flow rate of brine extraction. which implies a variable heat extraction rate, due to the variation of the LCZ temperature during the daily and seasonal cycles. $T_{\text {ein }}$ is fixed, while $T_{L C Z}$ is variable and is obtained from the thermal simulation of the pond. A quasi-static analysis can be made for the heat exchanger due to its low thermal inertia as compared to that of the pond, to give the instantaneous heat transfer as a function of the variable temperature of the LCZ, $T_{L C Z \text { : }}$

$$
Q_{e x t}=\frac{\left(T_{L C Z}-T_{e i n}\right)(1-B)}{\left(\frac{1}{m_{e} C p_{e}}-\frac{B}{m C_{p}}\right)}, \quad B=\exp \left(U A\left(\frac{1}{m C p}-\frac{1}{m_{e} C p_{e}}\right)\right)
$$


Given the mass flow rates and specific heats, the area and the overall heat transfer coefficient of a proposed heat exchanger, the exit temperatures of both fluids can be obtained as a function of time by means of equation (5), which is used as the heat extraction term in the model. From the record of exit temperature of the process fluid $\left(T_{\text {eout }}\right)$ along the simulation period we can determine the percentage of time in which a supporting source of energy is needed to comply with process requirements. Several cases were examined, looking for efficient use of solar energy. This means to keep the heat extraction rates high, but below the limit for instability and using a supporting energy source when necessary. The order of magnitude of the limit of extraction rates is presented in Table 5. For two pond sizes the sensitivity of the heat exchanger area to the mass flow rate is also reported in Table 5.

Plate heat exchangers are chosen for this application because of their flexibility to operate with variable heat transfer rates, and the possibility of easy cleaning. Stainless steel plates are chosen because of the nature of the fluids involved. The overall heat transfer coefficient is estimated to vary between 1300 and $1500 \mathrm{~W} / \mathrm{m}^{2}$ $\mathrm{K}$, according to [9].

Heat exchangers are assigned to meet process requirements for the different pond sizes according to the following lines. A heat exchanger is chosen for some nominal conditions, avoiding to assign undersized area. The nominal conditions are: Average $T_{L C Z}$ for a period of three years, return temperature $15^{\circ} \mathrm{C}$ below $T_{L C Z}$, $45^{\circ} \mathrm{C}$ for the entering process fluid, and given flow rates for both fluids.

With these process conditions, the area of heat exchanger is calculated by standard methods. Then the heat exchanger is tested for different mass flow rates. The efficiency of the solar pond under the resulting conditions is determined, and also the percent time in which suplementary heat source is needed. Finally, the Number of Transfer Units, NTU, is determined, trying to keept it below a value of 3 , to avoid oversizing. The heat exchangers and the outcome performance parameters for a few of the cases run are given as follows:

Table 5: Heat exchanger areas, pond efficiencies and time availability of different ponds as a function of mass flow rates at the exchanger.

\begin{tabular}{|l|l|l|l|l|l|}
\hline Pond area, $\mathrm{m}^{2}$ & $150 \times 150$ & $100 \times 100$ & $100 \times 100$ & $70 \times 70$ & $70 \times 70$ \\
\hline$m_{e}, m[\mathrm{~kg} / \mathrm{s}]$ & 18 and 16 & 9 and 10 & 7 and 7 & 4 and 4 & 6 and 6 \\
\hline $\mathrm{Q},[\mathrm{W}]$ & $0.99 \mathrm{MW}$ & $458 \mathrm{~kW}$ & $494 \mathrm{~kW}$ & $248 \mathrm{~kW}$ & $245 \mathrm{~kW}$ \\
\hline $\mathrm{U}\left[\mathrm{W} / \mathrm{m}^{2} \mathrm{~K}\right], \mathrm{A}\left[\mathrm{m}^{2}\right]$ & 1500,42 & 1300,19 & 1300,31 & 1300,18 & 1300,14 \\
\hline$\eta$ & 0.1413 & 0.148 & 0.16 & 0.164 & 0.162 \\
\hline$t_{w e}, \%$ & 43 & 50 & 44 & 40 & 41 \\
\hline NTU & 0.86 & 0.78 & 1.27 & 1.66 & 1.29 \\
\hline
\end{tabular}

From more extensive results a choice of suitable heat exchangers and operating conditions must be made. All cases are within the range of low values of NTU, in which an area increase results in increases in the heat transfer rate. 


\section{Conclusions}

A methodology is presented for selecting heat exchangers and operating conditions for a particular industrial process energized by solar ponds in northern Chile. It is based on long term modeling of temperature in the pond by means of heat balances. The difficulties in applying these devices to processes that require steady and stable conditions are a real challenge. For the particular case of a process located in northern Chile and requiring hot fluids at $60^{\circ} \mathrm{C}$, solar ponds alone can supply the required heat for $50 \%$ of the operating time, at the cost of a relatively low thermal efficiency. Higher efficiencies and times of autonomous operation can be achieved with processes needing lower temperature hot sources, such as absorption refrigeration. Transient thermal models are useful for defining process conditions in cases requiring matching of the energy requirements of a steady state process to the dynamics of an essentially transient energy collecting device as a solar pond or other renewable energy sources.

\section{References}

[1] Zangrando, F., On the stability of salt-gradient solar ponds. Solar Energy, 46, pp. 323-341, 1991.

[2] Leblanc. J., Akbarzadeh. A., Andrews. J., Lu, H. \& Golding, P., Heat extraction methods from salinity-gradient solar ponds and introduction of a novel system of heat extraction for improved efficiency. Solar Energy, 85, pp. 3103-3142, 2011.

[3] Corporación Nacional del Cobre, Chile, Planta Termosolar en División Gabriela Mistral, Diffusion Brochure, October 2013.

[4] Ministerio de energía, Departamento de Geofísica, Universidad de Chile. Explorador de energía solar. Recovered from http://walker.dgf.uchile.cl /Explorador/Solar2/

[5] Mansour, R., Nguyen, C., \& Galanis, N., Transient heat and mass transfer and long-term stability of a salt-gradient solar pond. Mechanics Research Communications 33, pp. 233-249, 2005.

[6] Rabl, A., Nielsen C.E., Solar ponds for space heating. Solar Energy, 17, pp. 1-12, 1974.

[7] Agha, K.R., The thermal characteristics and economic analysis of a solar pond coupled low temperature multi stage desalination plant, Solar Energy, 83, pp. 501-510, 2009.

[8] Meranda, D., \& Furfer, W.F., Elevation of the Boiling Point of Water by Salts at Saturation: Data and Correlation. Journal of Chemical and Engineering Data, 22, 1977.

[9] Kumar, A., \& Kishore, V., Construction and operational experience of a $6000 \mathrm{~m}^{2}$ solar pond at Kutch, India. Solar Energy, 65, pp. 237-249, 1998. 